\title{
Inducing an Order-Order Morphological Transition via Chemical Degradation of Amphiphilic Diblock Copolymer Nano-Objects
}

\author{
Liam P. D. Ratcliffe, ${ }^{* \dagger}$ Claudie Couchon, ${ }^{\dagger}$ Steven P. Armes, ${ }^{* \dagger}$ and Jos M. J. Paulusse ${ }^{*,+}$ \\ ${ }^{\dagger}$ Dainton Building, Department of Chemistry, The University of Sheffield, Brook Hill, Sheffield, South Yorkshire S3 7HF, United \\ Kingdom \\ ${ }^{\ddagger}$ Department of Biomaterials Science and Technology, MIRA Institute for Biomedical Technology and Technical Medicine, Faculty of \\ Science and Technology University of Twente, P.O. Box 217, 7500 AE Enschede, The Netherlands
}

Supporting Information

ABSTRACT: The disulfide-based cyclic monomer, 3-methylidene-1,9-dioxa-5,12,13-trithiacyclopentadecane-2,8-dione (MTC), is statistically copolymerized with 2-hydroxypropyl methacrylate to form a range of diblock copolymer nanoobjects via reversible addition-fragmentation chain transfer (RAFT) polymerization. Poly(glycerol monomethacrylate) (PGMA) is employed as the hydrophilic stabilizer block in
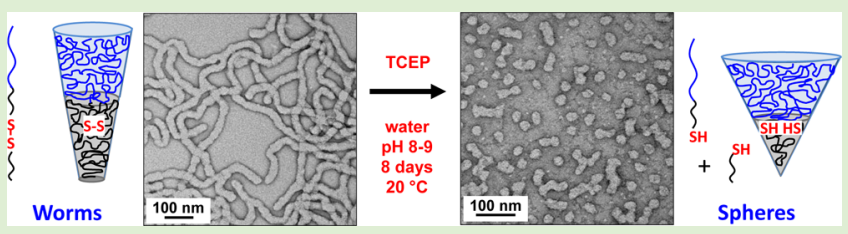
on the target degree of polymerization for the core-forming block. When relatively low levels $(<1$ mol \%) of MTC are incorporated, high monomer conversions (>99\%) are achieved and high blocking efficiencies are observed, as judged by ${ }^{1} \mathrm{H}$ NMR spectroscopy and gel permeation chromatography (GPC), respectively. However, the side reactions that are known to occur when cyclic allylic sulfides such as MTC are statistically copolymerized with methacrylic comonomers lead to relatively broad molecular weight distributions. Nevertheless, the worm-like nanoparticles obtained via PISA can be successfully transformed into spherical nanoparticles by addition of excess tris(2-carboxyethyl)phosphine (TCEP) at pH 8-9. Surprisingly, DLS and TEM studies indicate that the time scale needed for this order-order transition is significantly longer than that required for cleavage of the disulfide bonds located in the worm cores indicated by GPC analysis. This reductive degradation pathway may enable the use of these chemically degradable nanoparticles in biomedical applications, such as drug delivery systems and responsive biomaterials.

\section{INTRODUCTION}

Degradable polymers have been the subject of significant and sustained research, not least for their potential in the design of therapeutic devices such as temporary prostheses, scaffolds for tissue engineering and controlled drug delivery vehicles. ${ }^{1-4}$ This has resulted in the development of a diverse range of materials based on either naturally occurring or entirely synthetic feedstocks. ${ }^{5}$ The extent and rate of degradability of these materials is primarily determined by the type and number of cleavable chemical bonds that are incorporated within the polymer chains, as well as their precise location. ${ }^{6}$ Anhydride, ester, amide, and disulfide bonds have been successfully employed, enabling chemical degradation via exposure to either photo, thermal, mechanical, or chemical stimuli. ${ }^{1,2,5-9}$ To ensure that sufficiently high levels of degradability can be achieved, such labile bonds are incorporated into the polymer backbone using techniques such as step polymerization ${ }^{10-17}$ or ring-opening polymerization (ROP). ${ }^{15-23}$ Although significant progress has been made, conferring chemical degradability on vinyl polymers undoubtedly remains a significant technical challenge. $^{24}$

The development of reversible deactivation radical polymerization (RDRP) techniques such as nitroxide-mediated polymerization (NMP), ${ }^{25}$ atom transfer radical polymerization
(ATRP), ${ }^{26,27}$ and reversible addition-fragmentation chain transfer (RAFT) polymerization ${ }^{28}$ has led to the design of many new controlled-structure copolymers based on vinyl monomers. $^{29,30}$ Moreover, formulations based on polymerization-induced self-assembly (PISA) ${ }^{31-33}$ enable the efficient synthesis of a wide range of nano-objects at high solids (up to $50 \% \mathrm{w} / \mathrm{w})^{34}$ in either polar or non-polar solvents. ${ }^{34-37} \mathrm{~A}$ prototypical PISA formulation involves the RAFT aqueous dispersion polymerization of 2-hydroxypropyl methacrylate (HPMA) using a poly(glycerol monomethacrylate) (PGMA) macromolecular chain transfer agent (macro-CTA). ${ }^{38,39}$ Under certain conditions, PGMA-PHPMA diblock copolymer chains self-assemble in situ to produce worm-like micelles. ${ }^{37}$ These highly anisotropic nanoparticles form soft, free-standing aqueous gels at $20{ }^{\circ} \mathrm{C}$. Moreover, a morphological transformation from worms to spheres can be induced on cooling to $5{ }^{\circ} \mathrm{C}$. ${ }^{40,41}$ This order-order transition is fully reversible and enables convenient sterilization of such worm gels via cold ultrafiltration. ${ }^{38}$ Such worm gels are currently being evaluated for in vitro applications such as a long-term storage medium for

Received: April 14, 2016

Revised: May 25, 2016 
human stem cells ${ }^{42}$ and also for the cryopreservation of red blood cells. ${ }^{43}$ Nevertheless, the nondegradability of the methacrylic backbone is a major barrier for potential in vivo biomedical applications.

Several methodologies have been explored to circumvent this important problem. For example, branched degradable vinyl copolymers have been designed using disulfide, ${ }^{4,45}$ acetal, $^{46}$ or silyl ether ${ }^{47}$ comonomers. Alternatively, a central degradable unit can be introduced via ATRP by using a disulfide-based bifunctional initiator. ${ }^{48,49}$ Such approaches have been recently reviewed by Rikkou and Patrickios, who have focused on copolymers prepared via either living or pseudoliving techniques. ${ }^{50}$ Another strategy involves coupling telechelic polymers (typically via postpolymerization oxidation of thiols) to produce degradable materials. ${ }^{51-55}$ Alternatively, ringopening polymerization (ROP) of a cyclic monomer (containing a cleavable functionality such as an ester) has been combined with vinyl polymerization. For example, Frick and co-workers ${ }^{56}$ coupled the ROP of lactide with the anionic polymerization of isoprene to produce various $A B A$ triblock copolymers. Several groups have prepared bespoke RAFT CTAs that enable both ROP of lactide and controlled vinyl polymerization. ${ }^{57-59}$ Similar dual-functional nitroxides and ATRP initiators have also been utilized in this context. ${ }^{60}$

Mecerreyes et al. designed an acrylic monomer containing caprolactone functionality, making it suitable for both ROP and ATRP. ${ }^{61}$ This was subsequently polymerized to form cleavable branched structures. Li and Armes prepared highly branched methacrylic copolymers using a disulfide dimethacrylate comonomer that enabled the primary chains within the branched structure to be characterized via postpolymerization cleavage. ${ }^{62}$ A similar approach was used by Armes and coworkers to design chemically degradable poly(2-hydroxyethyl methacrylate)-based fibers. ${ }^{63}$

More recently, there has been growing interest in the radical ring-opening polymerization (RROP) ${ }^{64}$ of cyclic ketene acetals $^{65-68}$ and cyclic allylic sulfides. ${ }^{69-71}$ Such monomers can be copolymerized with vinyl monomers to afford chemically degradable vinyl copolymers. ${ }^{72,73}$ There are a number of literature reports utilizing RDRP techniques to (co)polymerize cyclic ketene acetals, including RAFT, ${ }^{74,75}$ NMP, ${ }^{76,77}$ and ATRP. ${ }^{78,79}$ However, as far as we are aware, there is currently only a single literature example describing the RDRP of cyclic allylic sulfides. ${ }^{80}$

In the present study, a small amount of a cyclic allylic sulfide, 3-methylidene-1,9-dioxa-5,12,13-trithiacyclopentadecane-2,8dione (MTC), ${ }^{80}$ is statistically copolymerized with 2 -hydroxypropyl methacrylate using an aqueous PISA formulation. $^{31,38,40}$ The MTC comonomer introduces a disulfide bond into the methacrylic backbone of the hydrophobic component of an amphiphilic diblock copolymer, which has been recently shown to exhibit excellent biocompatibility for various cell types, including human stem cells and red blood cells. $^{40,42,43}$ Subsequent reductive cleavage under appropriate conditions ${ }^{81}$ leads to a significantly shorter hydrophobic block, which is sufficient to produce a change in the morphology of the diblock copolymer nano-objects produced during PISA. In principle, such an order-order transition may be sufficient to allow a renal clearance mechanism, which suggests the possibility of in vivo biomedical applications.

\section{EXPERIMENTAL SECTION}

Materials. 2-Hydroxypropyl methacrylate (HPMA, 97\%) and 4,4'azobis(4-cyanopentanoic acid) (ACVA; V-501; 99\%) were purchased from Alfa Aesar (Heysham, U.K.) and used as received. Glycerol monomethacrylate (GMA, 99.8\%) was kindly donated by GEO Specialty Chemicals (Hythe, U.K.) and used without further purification. 3-Methylidene-1,9-dioxa-5,12,13-trithiacyclopentadecane2,8-dione (MTC) was synthesized as described elsewhere. ${ }^{80}$ 2-Cyano2-propyl benzodithioate (CPDB) was purchased from Strem Chemicals (Cambridge, U.K.) and tris(2-carboxyethyl)phosphine (TCEP hydrochloride, 99\%) was purchased from Amresco (Solon, Ohio, U.S.A.). Deuterated methanol $\left(\mathrm{CD}_{3} \mathrm{OD}\right)$ was purchased from Goss Scientific (Nantwich, U.K.). Sodium hydroxide pellets were purchased from VWR (Lutterworth, U.K.). Deionized water was used for all dispersion polymerizations. All other solvents were of HPLC quality, purchased from Fisher Scientific (Loughborough, U.K.) and used as received.

Synthesis and Purification of PGMA ${ }_{56}$ Macro-CTA. A typical protocol for the synthesis of PGMA $_{56}$ macro-CTA is as follows. To a round-bottomed flask containing CPDB RAFT agent (75\% purity, $0.020 \mathrm{~mol}, 6.03 \mathrm{~g})$, GMA monomer $(1.268 \mathrm{~mol}, 203.0 \mathrm{~g})$ and ethanol $(3.38 \mathrm{~mol}, 156.0 \mathrm{~g})$ was added to target a mean degree of polymerization (DP) of 63 . To this, ACVA initiator $(4.07 \mathrm{mmol}$, $1.14 \mathrm{~g}$; CTA/ACVA molar ratio $=5.0$ ) was added, and the resulting pink solution was sparged with $\mathrm{N}_{2}$ for 20 min before the sealed flask was immersed into an oil bath set at $70{ }^{\circ} \mathrm{C}$. After $140 \mathrm{~min}(69 \%$ conversion as judged by ${ }^{1} \mathrm{H}$ NMR), the GMA polymerization was quenched by immersing the flask in an ice bath and exposing the reaction solution to air. The crude polymer solution was then precipitated into a 10 -fold excess of DCM (twice) and then washed three times with DCM before being dissolved in water and lyophilized overnight. ${ }^{1} \mathrm{H}$ NMR analysis indicated a mean DP of 56 for this PGMA macro-CTA. Taking into account the target DP of 63 and the GMA conversion of $69 \%$, this suggests a CTA efficiency of $76 \%$. DMF GPC analysis (refractive index detector; vs a series of poly(methyl methacrylate) calibration standards) indicated $M_{\mathrm{n}}$ and $M_{\mathrm{w}} / M_{\mathrm{n}}$ values of $14300 \mathrm{~g} \mathrm{~mol}^{-1}$ and 1.14 , respectively.

RAFT Synthesis of PGMA ${ }_{56}-\mathrm{P}\left(\mathrm{HPMA}_{180}\right.$-stat-MTC $\left.\mathrm{MT}_{0.9}\right)$ Diblock Copolymer. A typical protocol for the synthesis of $\mathrm{PGMA}_{56}$ $\mathrm{P}\left(\mathrm{HPMA}_{180^{-} \text {stat-MTC }} \mathrm{MT}_{0.9}\right)$ statistical diblock copolymer is as follows: MTC monomer $(0.0036 \mathrm{~g}, 0.011 \mathrm{mmol})$ was added to a glass vial or round bottomed flask, followed by HPMA monomer $(0.3388 \mathrm{~g}, 2.35$ mmol), PGMA ${ }_{56}$ macro-CTA ( $\left.0.12 \mathrm{~g}, 0.013 \mathrm{mmol}\right)$, and water $(4.17 \mathrm{~g}$, to produce $10 \% \mathrm{w} / \mathrm{w}$ total solids). ACVA was then added $(0.9 \mathrm{mg}$, $0.003 \mathrm{mmol}$, macro-CTA/ACVA molar ratio $=4.0$ ), and the solution was sparged with $\mathrm{N}_{2}$ for $30 \mathrm{~min}$. The flask was sealed and immersed in an oil bath set at $70{ }^{\circ} \mathrm{C}$ and stirred for $16 \mathrm{~h}$ to ensure complete monomer conversion. The polymerization was quenched by exposure to air and cooling the flask to $20^{\circ} \mathrm{C}$.

Addition of Reducing Agent to $\mathrm{PGMA}_{56}-\mathrm{P}\left(\mathrm{HPMA}_{180}\right.$-stat$\mathrm{MTC}_{0.9}$ ) Diblock Copolymer. The protocol is as follows: To $\mathrm{PGMA}_{56}-\mathrm{P}\left(\mathrm{HPMA}_{180}\right.$-stat-MTC $\left.\mathrm{M}_{0.9}\right)$ statistical diblock copolymer (3.00 $\mathrm{g}$ of $10 \% \mathrm{w} / \mathrm{w}$ dispersion, $0.0076 \mathrm{mmol}$ of MTC) TCEP reducing agent $(0.011 \mathrm{~g}, 0.038 \mathrm{mmol}$, TCEP $/ \mathrm{MTC}$ molar ratio $=5)$ was added, followed by $1 \mathrm{M} \mathrm{NaOH}$ solution to adjust the final $\mathrm{pH}$ to between 8 and 9. The reaction solution was agitated on a roller at $20{ }^{\circ} \mathrm{C}$ and sampled as required.

RAFT Synthesis of PGMA ${ }_{56}-$ PHPMA $_{180}$ Diblock Copolymer. A typical protocol for the synthesis of PGMA $_{56}$ PHPMA $_{180}$ statistical diblock copolymer is as follows: PGMA $_{56}$ macro-CTA (0.1124 g, 0.012 $\mathrm{mmol})$, HPMA monomer $(0.3122 \mathrm{~g}, 2.15 \mathrm{mmol})$, and water $(3.79 \mathrm{~g}$, to produce $10 \% \mathrm{w} / \mathrm{w}$ total solids) were added to a glass vial or round bottomed flask. ACVA was then added $(0.8 \mathrm{mg}, 0.003 \mathrm{mmol}$, macroCTA/ACVA molar ratio $=4.0$ ), and the solution was sparged with $\mathrm{N}_{2}$ for $30 \mathrm{~min}$. The flask was sealed and immersed in an oil bath set at 70 ${ }^{\circ} \mathrm{C}$ and stirred for $16 \mathrm{~h}$ to ensure complete monomer conversion. The polymerization was quenched by exposure to air and cooling the flask to $20{ }^{\circ} \mathrm{C}$. 

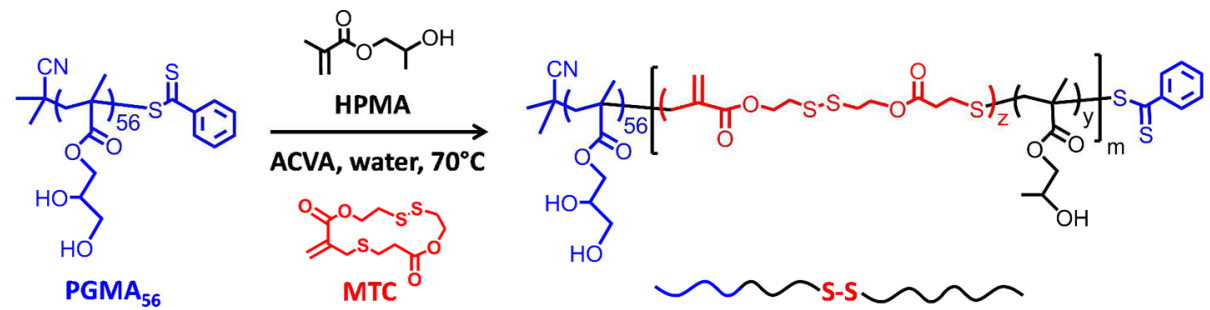

Polymerization-Induced Self-Assembly (PISA)
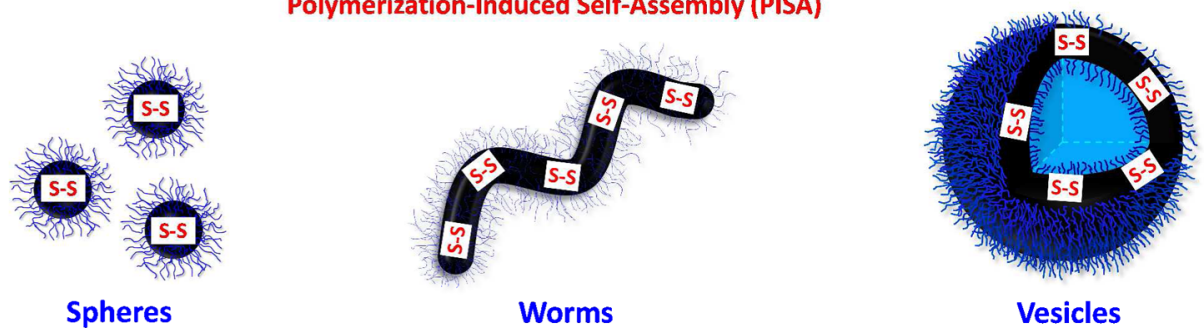

Increasing DP $(Y+Z)$

Figure 1. Synthesis of $\mathrm{PGMA}_{56}-\mathrm{P}\left(\mathrm{HPMA}_{y}\right.$-stat-MTC $)$ diblock copolymer nano-objects via RAFT statistical copolymerization of HPMA with MTC in aqueous solution at $70^{\circ} \mathrm{C}$. As the overall target DP $(y+z)$ of the $\mathrm{P}(\mathrm{HPMA}$-stat-MTC) core-forming block is increased, polymerization-induced self-assembly (PISA) occurs to produce either spherical, worm-like, or vesicular nano-objects with cleavable disulfide bonds being located within the hydrophobic P(HPMA-stat-MTC) chains.

Copolymer Characterization. ${ }^{1} H$ NMR Spectroscopy. All NMR spectra were recorded using a $400 \mathrm{MHz}$ Bruker Avance-400 spectrometer (64 scans per sample) in $\mathrm{CD}_{3} \mathrm{OD}$ or $\mathrm{CDCl}_{3}$.

Gel Permeation Chromatography (GPC). Polymer molecular weights and polydispersities were determined using a DMF GPC instrument operating at $60{ }^{\circ} \mathrm{C}$ that comprised two Polymer Laboratories PL gel $5 \mu \mathrm{m}$ Mixed C columns and one PL gel $5 \mu \mathrm{m}$ guard column connected in series to an Agilent Technologies 1260 Infinity multidetector suite (refractive index detector only) and an Agilent Technologies 1260 ISO pump fitted with a 1260 ALS autosampler. The GPC eluent was HPLC-grade DMF containing 10 $\mathrm{mM} \mathrm{LiBr}$ and was filtered prior to use. The flow rate used was $1.0 \mathrm{~mL}$ $\mathrm{min}^{-1}$ and DMSO was used as a flow-rate marker. Calibration was conducted using a series of 10 near-monodisperse poly(methyl methacrylate $)$ standards $\left(M_{\mathrm{n}}=625-618000 \mathrm{~g} \mathrm{~mol}^{-1}, K=2.094 \times\right.$ $10^{-3}, \alpha=0.642$ ). Chromatograms were analyzed using Agilent Technologies GPC/SEC software version 1.2.

Transmission Electron Microscopy (TEM). Reaction mixtures were diluted at $20{ }^{\circ} \mathrm{C}$ to generate $0.60 \% \mathrm{w} / \mathrm{w}$ dispersions. Copper TEM grids (Agar Scientific, U.K.) were surface-coated in-house to yield a thin film of amorphous carbon. The grids were then plasma glowdischarged for $40 \mathrm{~s}$ to create a hydrophilic surface. Each aqueous diblock copolymer dispersion $(11 \mu \mathrm{L})$ was placed onto a freshly glowdischarged grid for $1 \mathrm{~min}$ and then blotted with filter paper to remove excess solution. To stain the deposited nanoparticles, a $0.75 \% \mathrm{w} / \mathrm{w}$ aqueous solution of uranyl formate $(11 \mu \mathrm{L})$ was placed via micropipette on the sample-loaded grid for $15 \mathrm{~s}$ and then carefully blotted to remove excess stain. Each grid was then carefully dried using a vacuum hose. Imaging was performed at $100 \mathrm{kV}$ using a Phillips CM100 instrument equipped with a Gatan $1 \mathrm{k}$ CCD camera.

Dynamic Light Scattering (DLS). Intensity-average hydrodynamic diameters of the dispersions were obtained by DLS using a Malvern Zetasizer NanoZS instrument. Dilute aqueous dispersions $(0.25 \% \mathrm{w} /$ w) were analyzed using disposable cuvettes, and all data were averaged over three consecutive runs.

\section{RESULTS AND DISCUSSION}

Paulusse et al. have reported the statistical copolymerization of MTC with methyl methacrylate, 2-hydroxyethyl methacrylate, or 2-dimethylaminoethyl methacrylate using RAFT solution polymerization in either chlorobenzene or dimethylforma- mide. ${ }^{80}$ Higher levels of MTC in the comonomer feed led to a gradual loss of control over the molecular weight distribution and also produced lower comonomer conversions. Bearing this prior study in mind, a small amount of MTC was statistically copolymerized with HPMA to introduce chemically degradable disulfide units into the methacrylic backbone of the predominantly PHPMA core-forming block using a RAFT aqueous dispersion polymerization formulation (see Figure 1).

First, a PGMA $_{56}$ macro-CTA was prepared via RAFT solution polymerization in ethanol, as previously described. ${ }^{82}$ Then the statistical copolymerization of MTC with HPMA was conducted using this macro-CTA, with 2 mol \% MTC being utilized relative to the HPMA target DP of 180 . The resulting diblock copolymer had a relatively broad molecular weight distribution $\left(M_{\mathrm{w}} / M_{\mathrm{n}}=1.52\right.$, as judged by DMF GPC, see Figure S1) compared to similar PGMA ${ }_{56}$ PHPMA $_{y}$ copolymers prepared in the absence of any MTC. ${ }^{39,83}$ Moreover, the overall comonomer conversion was only $84 \%$ after $16 \mathrm{~h}$ at $70{ }^{\circ} \mathrm{C}$, as judged by ${ }^{1} \mathrm{H}$ NMR spectroscopy. When the MTC content was reduced to $1 \mathrm{~mol} \%$, the final conversion exceeded $98 \%$, but the dispersity was only slightly reduced $\left(M_{\mathrm{w}} / M_{\mathrm{n}}=1.44\right)$. Such relatively high $M_{\mathrm{w}} / M_{\mathrm{n}}$ values may explain why only mixed phases (e.g., spheres plus worms or vesicles plus worms) were observed when these dispersions were analyzed using TEM (see Figure S2). Fortunately, further lowering the MTC content to $0.50 \mathrm{~mol} \%$ led to slightly lower dispersities $\left(M_{\mathrm{w}} /\right.$ $M_{\mathrm{n}}<1.40$ ), and more than $99 \%$ comonomer conversion was achieved in all cases. Moreover, relatively pure spherical, wormlike, or vesicular morphologies could be obtained (see Figure S3), although rather higher core-forming block DPs were required to produce worm and vesicle phases compared to that needed for similar PGMA-PHPMA diblock copolymers prepared in the absence of MTC (see Figure S4). Interestingly, the DP range over which the worm phase is observed appears to be significantly broader for PISA syntheses conducted in the presence of MTC. ${ }^{39}$ Both observations are most likely related to the higher copolymer dispersities that arise from side reactions (e.g., vinyl addition ${ }^{71}$ ) that are known to occur when 
(a)

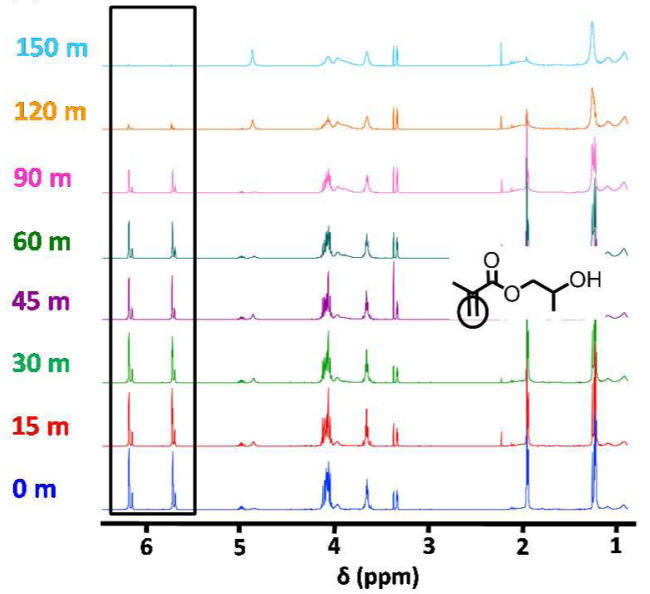

(b)

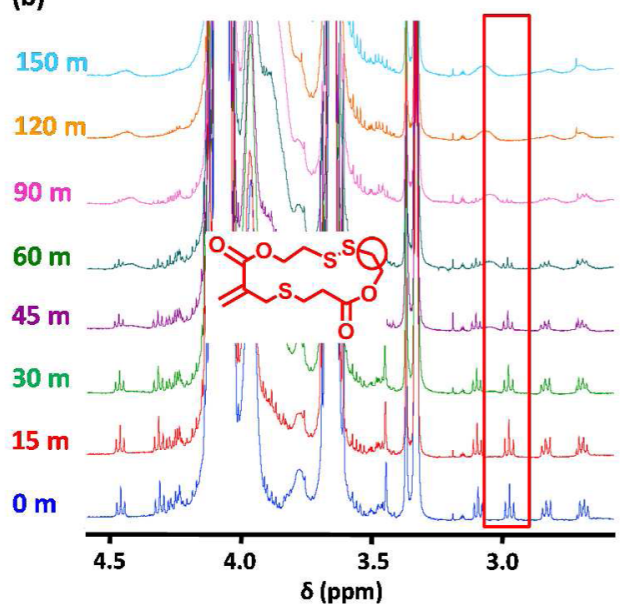

(c)

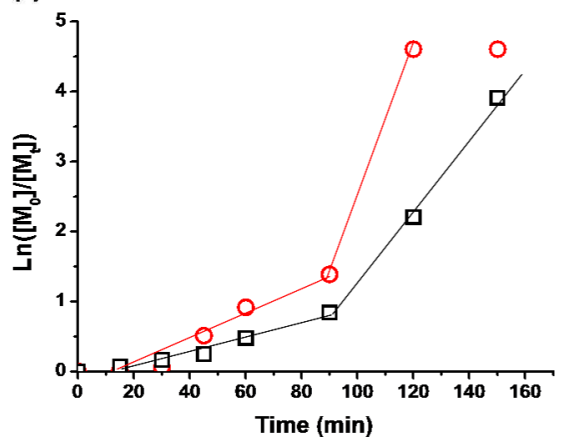

Figure 2. $(\mathrm{a}, \mathrm{b}){ }^{1} \mathrm{H}$ NMR spectra obtained for a $\mathrm{PGMA}_{56}-\mathrm{P}\left(\mathrm{HPMA}_{170^{-}}\right.$ stat- $\left.\mathrm{MTC}_{0.85}\right)$ copolymer synthesis sampled at various time periods during RAFT statistical copolymerization of HPMA with MTC at 70 ${ }^{\circ} \mathrm{C}$ and $10 \% \mathrm{w} / \mathrm{w}$ solids in aqueous solution, indicating the signals utilized to produce the graph shown in (c). (c) Rate of consumption (as judged by ${ }^{1} \mathrm{H}$ NMR) of HPMA (black squares) and MTC (red circles) for a $\mathrm{PGMA}_{56} \mathrm{P}\left(\mathrm{HPMA}_{170}\right.$-stat-MTC $\left.\mathrm{M}_{0.85}\right)$ copolymer sampled at various time periods during RAFT polymerization at $70{ }^{\circ} \mathrm{C}$ and $10 \%$ $\mathrm{w} / \mathrm{w}$ in water.

cyclic allylic sulfides are statistically copolymerized with methacrylic monomers via RAFT. ${ }^{80}$ Nonetheless, in addition to the expected dependence on the degree of polymerization (DP) of the PHPMA block and the concentration at which the HPMA polymerization is conducted, it is clear that the copolymer morphology is also sensitive to the proportion of the more hydrophobic MTC comonomer. ${ }^{39}$ After conducting (a)

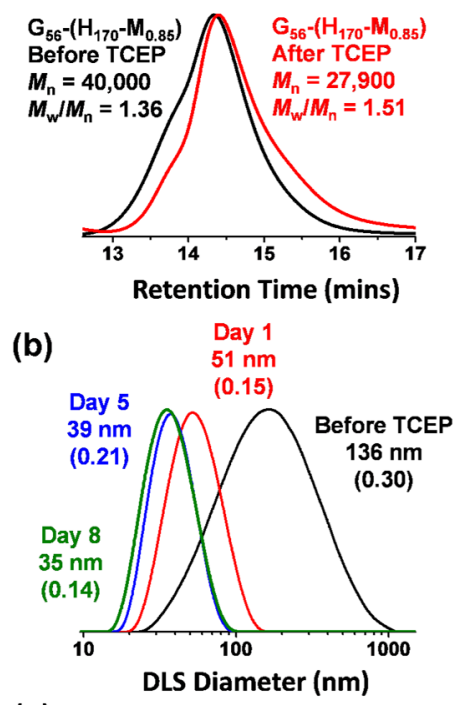

(c)

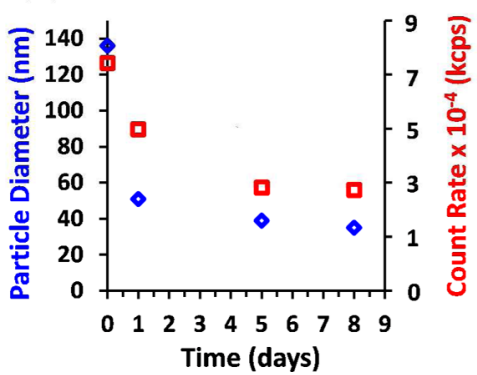

Figure 3. (a) DMF GPC curves recorded for $\mathrm{PGMA}_{56}-\mathrm{P}\left(\mathrm{HPMA}_{170^{-}}\right.$ stat-MTC $\left.\mathrm{MT}_{0.85}\right)$ [denoted as $\mathrm{G}_{56}-\left(\mathrm{H}_{170^{-}}-\mathrm{M}_{0.85}\right)$ for brevity] copolymers prepared via RAFT copolymerization of MTC with HPMA using a $\mathrm{PGMA}_{56}$ macro-CTA at $70{ }^{\circ} \mathrm{C}$ before (black curve) and after (red curve) exposure to TCEP (TCEP/MTC molar ratio $=5.0)$ at $\mathrm{pH} 8-9$ for 8 days at $20{ }^{\circ} \mathrm{C}$. (b) Evolution of intensity-average particle size distributions (determined for $0.20 \% \mathrm{w} / \mathrm{w}$ aqueous copolymer dispersions) before and after a $10 \% \mathrm{w} / \mathrm{w}$ aqueous dispersion of $\mathrm{PGMA}_{56}-\mathrm{P}\left(\mathrm{HPMA}_{170^{-}}\right.$stat-MTC $\left.{ }_{0.85}\right)$ was exposed to TCEP (TCEP/ MTC molar ratio $=5.0$ ) at $\mathrm{pH} 8-9$ for 1,5 , or 8 days at $20^{\circ} \mathrm{C}$. The corresponding DLS polydispersities (PDI) are indicated in brackets. (c) DLS data plotted vs time (days after TCEP addition), demonstrating the observed reduction in the intensity-average diameter and count rate.

some scouting experiments, we targeted $\mathrm{P}\left(\mathrm{HPMA}_{170^{-}}\right.$stat$\mathrm{MTC}_{0.85}$ ), which formed a predominantly worm-like morphology. In principle, cleaving the disulfide bonds located in the methacrylic backbone should significantly reduce the coreforming block DP and hence drive a worm-to-sphere transition. Comonomer conversions typically reached more than $99 \%$ within approximately $3 \mathrm{~h}$ at $70{ }^{\circ} \mathrm{C}$. However, the copolymerization was allowed to proceed for a further $13 \mathrm{~h}$ to ensure the highest possible conversion, since this did not appear to be detrimental to the overall level of control (see Figure S5). The relative copolymerization rates for HPMA and MTC indicated that the latter comonomer initially reacted slightly faster than HPMA but overall was incorporated more or less statistically into the core-forming block (see ${ }^{1} \mathrm{H}$ NMR spectra in Figure 2).

Addition of tris (2-carboxyethyl)phosphine (TCEP; TCEP/ MTC molar ratio $=5.0)$ to a stirred $10 \% \mathrm{w} / \mathrm{w}$ aqueous dispersion of $\mathrm{PGMA}_{56} \mathrm{P}\left(\mathrm{HPMA}_{170}\right.$-stat- $\left.\mathrm{MTC}_{0.85}\right)$ for $16 \mathrm{~h}$ at $\mathrm{pH} 8-9$ led to a marked reduction in $M_{\mathrm{n}}$ from 40000 to 27900 


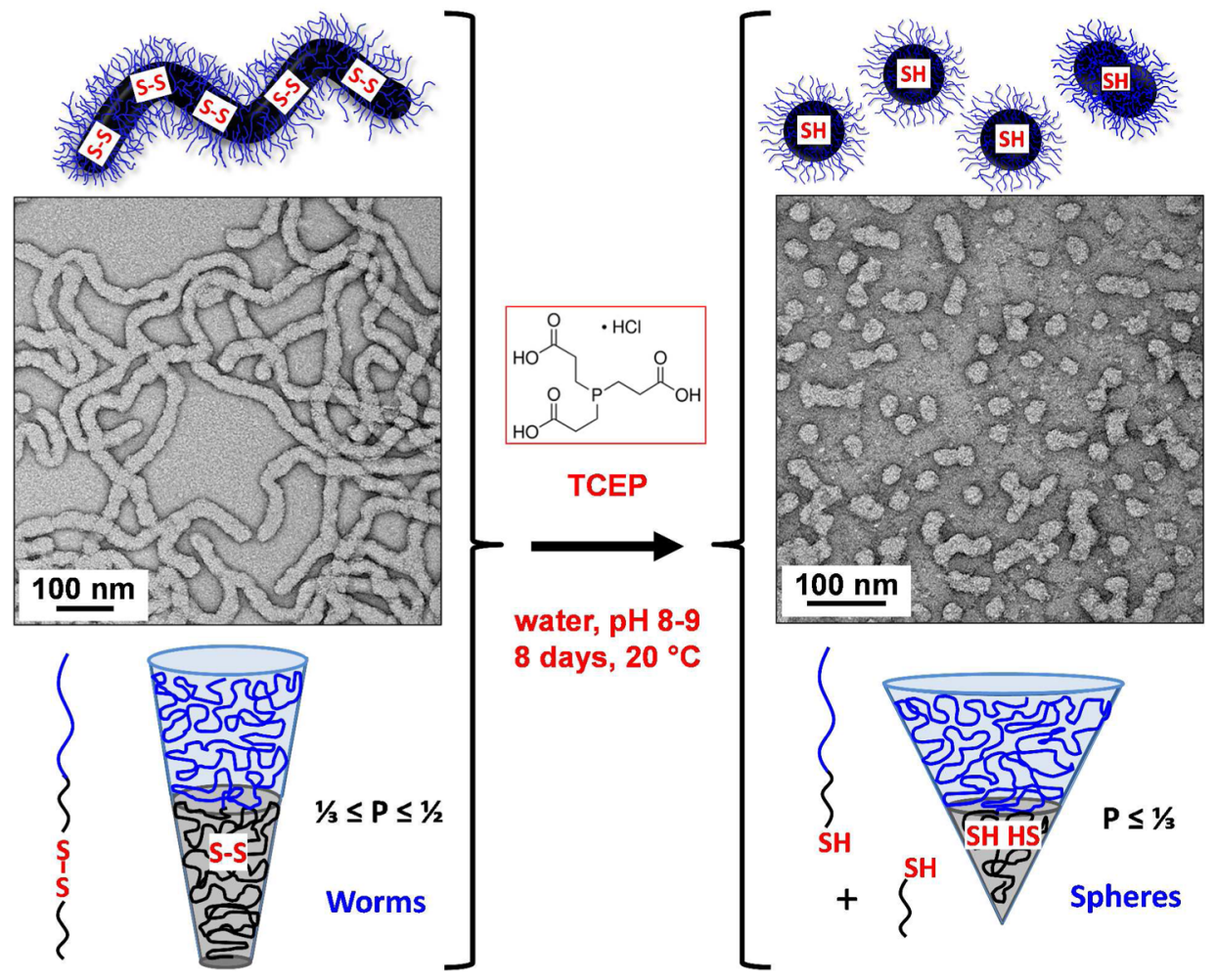

Figure 4. TEM images obtained for a $0.20 \% \mathrm{w} / \mathrm{w}$ aqueous dispersion of $\mathrm{PGMA}_{56} \mathrm{P}\left(\mathrm{HPMA}_{170}{ }^{-}\right.$stat-MTC $\left.\mathrm{M}_{0.85}\right)$ before and after exposure to TCEP $(\mathrm{TCEP} / \mathrm{MTC}$ molar ratio $=5.0)$ at $\mathrm{pH} 8-9$ for 8 days at $20^{\circ} \mathrm{C}$. Cartoon representation of the worm-to-sphere transition observed for a $10 \% \mathrm{w} / \mathrm{w}$ aqueous dispersion of $\mathrm{PGMA}_{56}-\mathrm{P}\left(\mathrm{HPMA}_{170}\right.$-stat-MTC $\left.\mathrm{MP}_{0.85}\right)$ worms on exposure to excess TCEP $(\mathrm{TCEP} / \mathrm{MTC}$ molar ratio $=5.0)$ at $\mathrm{pH} 8-9$ for 8 days at $20^{\circ} \mathrm{C}$ and the corresponding reduction in the packing parameter.

$\mathrm{g} \mathrm{mol}^{-1}$ with a concomitant increase in $M_{\mathrm{w}} / M_{\mathrm{n}}$ from 1.36 to 1.51 , see Figure 3a. This reduction in copolymer $M_{n}$ is consistent with the relatively low level of MTC that is (approximately) statistically incorporated into the hydrophobic core-forming block. In contrast, no molecular weight reduction was observed in a control experiment whereby a $\mathrm{PGMA}_{56}$ $\mathrm{PHPMA}_{180}$ copolymer prepared in the absence of any MTC was treated with TCEP under the same conditions (see Figure S6).

This reduction in molecular weight was also sufficient to produce an irreversible worm-to-sphere transition (see DLS and TEM data shown in Figures 3b,c and 4, respectively). The final morphology is in good agreement with the relatively small spherical particles obtained for a $\mathrm{PGMA}_{56}-\mathrm{PHPMA}_{85}$ copolymer prepared in the absence of MTC (see Figure S7, DLS diameter $=26 \mathrm{~nm}$ and PDI $=0.10)$. This reference copolymer was selected because its core-forming block DP is approximately half that of the original $\mathrm{PGMA}_{56} \mathrm{P}\left(\mathrm{HPMA}_{170^{-}}\right.$stat$\left.\mathrm{MTC}_{0.85}\right)$. Interestingly, the worm-to-sphere transformation is relatively slow at $20{ }^{\circ} \mathrm{C}$, requiring 5-8 days at $\mathrm{pH} 8-9$ for the initial "sphere-equivalent" particle diameter of $136 \mathrm{~nm}$ for the worms to be reduced to a final pseudo-spherical particle diameter of $35 \mathrm{~nm}$. Significant reductions in count rate (from 74300 to $27300 \mathrm{kcps}$ ) and DLS polydispersity (from 0.30 to 0.14 ) were also observed for this morphological transition, as expected (see Figure S3c). It is not yet clear why the experimental time scales for disulfide bond cleavage and the corresponding change in morphology are so different, but it is perhaps worth emphasizing that this phenomenon proved to be reproducible. Relatively fast reductive cleavage of the disulfide bonds was anticipated: PHPMA chains are known to be highly plasticized with water in similar PGMA-PHPMA worms, which should enable rapid ingress of the TCEP reagent. ${ }^{40}$ However, the change in copolymer morphology from worms to (mainly) spheres as a result of the reduction in the packing parameter is remarkably slow. This may indicate some degree of recombination of free thiols to form disulfides within the worms. Alternatively, the relatively high dispersity of the copolymer chains may play a role: the statistical distribution of the MTC residues along the core-forming block (see copolymerization kinetic data in Figure 2) means that there is minimal change in the packing parameter for a significant fraction of the copolymer chains. ${ }^{84}$ In fact, assuming a Poisson distribution it is estimated that up to $43 \%$ of the copolymer chains may not contain any MTC comonomer. Nevertheless, TEM studies in Figure 4 confirm the DLS data shown in Figure 3: the original worms are indeed eventually converted into spheres (plus some dimers and trimers) on addition of excess TCEP at $\mathrm{pH} 8-9$.

\section{CONCLUSIONS}

MTC has been statistically copolymerized with HPMA using an aqueous PISA formulation to afford a series of chemically degradable diblock copolymer nano-objects. RAFT control was gradually lost and the overall comonomer conversion was reduced when using higher levels of MTC comonomer and only a relatively low level of MTC $(<1 \mathrm{~mol} \%)$ could be tolerated if relatively well-defined spherical, worm-like or vesicular phases were required. Despite these synthetic limitations, using MTC as a comonomer enabled disulfide bonds to be incorporated into the methacrylic backbone of the hydrophobic core-forming block. In the case of the worm 
morphology, subsequent cleavage of these disulfide bonds using excess TCEP resulted in a sufficient reduction in $M_{\mathrm{n}}$ to induce an irreversible worm-to-sphere transition, which was confirmed using TEM and DLS. In principle, this chemical degradation pathway could produce spherical nanoparticles that are sufficiently small to allow renal clearance from the body, boding well for the use of these diblock copolymer nanoobjects in biomedical applications.

\section{ASSOCIATED CONTENT}

\section{S Supporting Information}

The Supporting Information is available free of charge on the ACS Publications website at DOI: 10.1021/acs.biomac.6b00540.

GPC traces for $\mathrm{PGMA}_{56} \mathrm{P}\left(\mathrm{HPMA}_{180}\right.$-stat-MTC $\left.\mathrm{MT}_{z}\right)$ containing $0.5,1.0$, or $2.0 \mathrm{~mol} \%$ MTC, TEM images of PGMA $_{x}-\mathrm{P}\left(\mathrm{HPMA}_{y}\right.$-stat-MTC $\left.{ }_{z}\right)$ with 0.5 or $1.0 \mathrm{~mol} \%$ MTC, TEM images, and GPC data for PGMA $_{56}$ $\mathrm{P}\left(\mathrm{HPMA}_{180}\right.$-stat-MTC $\left.\mathrm{MT}_{0.9}\right)$ and $\mathrm{PGMA}_{56}-\mathrm{PHPMA}_{180}$. GPC traces for $\mathrm{PGMA}_{56} \mathrm{P}\left(\mathrm{HPMA}_{180}\right.$-stat-MTC $\left.\mathrm{MT}_{0.9}\right)$ and PGMA $_{56}-\mathrm{PHPMA}_{180}$ before and after addition of excess TCEP, TEM, and GPC data for PGMA ${ }_{56}-$ PHPMA $_{85}$ and ${ }^{1} \mathrm{H}$ and ${ }^{13} \mathrm{C}$ NMR spectra for MTC monomer (PDF).

\section{AUTHOR INFORMATION}

\section{Corresponding Authors}

*E-mail: s.p.armes@sheffield.ac.uk.

*E-mail: j.m.j.paulusse@utwente.nl.

*E-mail: 1.p.ratcliffe@sheffield.ac.uk.

\section{Notes}

The authors declare no competing financial interest.

\section{ACKNOWLEDGMENTS}

EPSRC is thanked for postdoctoral support of LPDR (EP/ K030949/1). S.P.A. thanks the European Research Council for a five-year Advanced Investigator Grant (PISA 320372). We thank the four reviewers of this manuscript for their helpful comments.

\section{REFERENCES}

(1) Nair, L. S.; Laurencin, C. T. Prog. Polym. Sci. 2007, 32, 762-798.

(2) Uhrich, K. E.; Cannizzaro, S. M.; Langer, R. S.; Shakesheff, K. M. Chem. Rev. 1999, 99, 3181-3198.

(3) Goldberg, M.; Langer, R.; Jia, X. J. Biomater. Sci., Polym. Ed. 2007, 18, 241-268.

(4) Guo, B.; Glavas, L.; Albertsson, A.-C. Prog. Polym. Sci. 2013, 38, $1263-1286$.

(5) Chandra, R.; Rustgi, R. Prog. Polym. Sci. 1998, 23, 1273-1335.

(6) Göpferich, A. Biomaterials 1996, 17, 103-114.

(7) Edlund, U.; Albertsson, A. C. Adv. Drug Delivery Rev. 2003, 55, 585-609.

(8) Pasparakis, G.; Manouras, T.; Vamvakaki, M.; Argitis, P. Nat. Commun. 2014, 5, n/a.

(9) Zhang, Q.; Re Ko, N.; Kwon Oh, J. Chem. Commun. 2012, 48, $7542-7552$.

(10) Paramonov, S. E.; Bachelder, E. M.; Beaudette, T. T.; Standley, S. M.; Lee, C. C.; Dashe, J.; Fréchet, J. M. J. Bioconjugate Chem. 2008, 19, 911-919.

(11) Bettinger, C. J.; Bruggeman, J. P.; Borenstein, J. T.; Langer, R. S. Biomaterials 2008, 29, 2315-2325.

(12) Tamada, J.; Langer, R. J. Biomater. Sci., Polym. Ed. 1992, 3, 315353.
(13) Freed, L. E.; Vunjak-Novakovic, G.; Biron, R. J.; Eagles, D. B.; Lesnoy, D. C.; Barlow, S. K.; Langer, R. Bio/Technology 1994, 12, 689-693.

(14) Wang, Y.; Ameer, G. A.; Sheppard, B. J.; Langer, R. Nat. Biotechnol. 2002, 20, 602-606.

(15) Lendlein, A.; Langer, R. Science 2002, 296, 1673-1676.

(16) Williams, C. K. Chem. Soc. Rev. 2007, 36, 1573-1580.

(17) Nederberg, F.; Zhang, Y.; Tan, J. P. K.; Xu, K.; Wang, H.; Yang, C.; Gao, S.; Guo, X. D.; Fukushima, K.; Li, L.; Hedrick, J. L.; Yang, Y.Y. Nat. Chem. 2011, 3, 409-414.

(18) Gref, R.; Minamitake, Y.; Peracchia, M.; Trubetskoy, V.; Torchilin, V.; Langer, R. Science 1994, 263, 1600-1603.

(19) Barrera, D. A.; Zylstra, E.; Lansbury, P. T.; Langer, R. Macromolecules 1995, 28, 425-432.

(20) Govender, T.; Stolnik, S.; Garnett, M. C.; Illum, L.; Davis, S. S. J. Controlled Release 1999, 57, 171-185.

(21) Albertsson, A.-C.; Varma, I. K. Biomacromolecules 2003, 4, $1466-1486$.

(22) Odelius, K.; Plikk, P.; Albertsson, A.-C. Biomacromolecules 2005, 6, 2718-2725.

(23) Coulembier, O.; Degée, P.; Hedrick, J. L.; Dubois, P. Prog. Polym. Sci. 2006, 31, 723-747.

(24) Delplace, V.; Nicolas, J. Nat. Chem. 2015, 7, 771-784.

(25) Hawker, C. J.; Barclay, G. G.; Orellana, A.; Dao, J.; Devonport, W. Macromolecules 1996, 29, 5245-5254.

(26) Kato, M.; Kamigaito, M.; Sawamoto, M.; Higashimura, T. Macromolecules 1995, 28, 1721-1723.

(27) Wang, J.-S.; Matyjaszewski, K. J. Am. Chem. Soc. 1995, 117, 5614-5615.

(28) Chiefari, J.; Chong, Y. K.; Ercole, F.; Krstina, J.; Jeffery, J.; Le, T. P. T.; Mayadunne, R. T. A.; Meijs, G. F.; Moad, C. L.; Moad, G.; Rizzardo, E.; Thang, S. H. Macromolecules 1998, 31, 5559-5562.

(29) Braunecker, W. A.; Matyjaszewski, K. Prog. Polym. Sci. 2007, 32, 93-146.

(30) Zetterlund, P. B.; Thickett, S. C.; Perrier, S.; Bourgeat-Lami, E.; Lansalot, M. Chem. Rev. 2015, 115, 9745-9800.

(31) Warren, N. J.; Armes, S. P. J. Am. Chem. Soc. 2014, 136, 1017410185.

(32) Charleux, B.; Delaittre, G.; Rieger, J.; D’Agosto, F. Macromolecules 2012, 45, 6753-6765.

(33) Derry, M. J.; Fielding, L. A.; Armes, S. P. Prog. Polym. Sci. 2016, $52,1-18$.

(34) Ratcliffe, L. P. D.; McKenzie, B. E.; Le Bouëdec, G. M. D.; Williams, C. N.; Brown, S. L.; Armes, S. P. Macromolecules 2015, 48, 8594-8607.

(35) Zehm, D.; Ratcliffe, L. P. D.; Armes, S. P. Macromolecules 2013, 46, 128-139.

(36) Ratcliffe, L. P. D.; Blanazs, A.; Williams, C. N.; Brown, S. L.; Armes, S. P. Polym. Chem. 2014, 5, 3643-3655.

(37) Kang, Y.; Pitto-Barry, A.; Maitland, A.; O’Reilly, R. K. Polym. Chem. 2015, 6, 4984-4992.

(38) Li, Y.; Armes, S. P. Angew. Chem., Int. Ed. 2010, 49, 4042-4046.

(39) Blanazs, A.; Ryan, A. J.; Armes, S. P. Macromolecules 2012, 45, $5099-5107$.

(40) Blanazs, A.; Verber, R.; Mykhaylyk, O. O.; Ryan, A. J.; Heath, J. Z.; Douglas, C. W. I.; Armes, S. P. J. Am. Chem. Soc. 2012, 134, 97419748.

(41) Verber, R.; Blanazs, A.; Armes, S. P. Soft Matter 2012, 8, 99159922.

(42) Canton, I.; Warren, N. J.; Chahal, A.; Amps, K.; Wood, A.; Weightman, R.; Wang, E.; Moore, H.; Armes, S. P. ACS Cent. Sci. 2016, 2, 65-74.

(43) Mitchell, D. E.; Lovett, J. R.; Armes, S. P.; Gibson, M. I. Angew. Chem., Int. Ed. 2016, 55, 2801-2804.

(44) Oh, J. K.; Siegwart, D. J.; Lee, H.-i.; Sherwood, G.; Peteanu, L.; Hollinger, J. O.; Kataoka, K.; Matyjaszewski, K. J. Am. Chem. Soc. 2007, $129,5939-5945$.

(45) Tsarevsky, N. V.; Matyjaszewski, K. Macromolecules 2005, 38, 3087-3092. 
(46) Cohen, J. L.; Almutairi, A.; Cohen, J. A.; Bernstein, M.; Brody, S. L.; Schuster, D. P.; Fréchet, J. M. J. Bioconjugate Chem. 2008, 19, 876881.

(47) Themistou, E.; Patrickios, C. S. Macromolecules 2004, 37, 67346743.

(48) Tsarevsky, N. V.; Matyjaszewski, K. Macromolecules 2002, 35, 9009-9014.

(49) Li, C.; Madsen, J.; Armes, S. P.; Lewis, A. L. Angew. Chem., Int. Ed. 2006, 45, 3510-3513.

(50) Rikkou, M. D.; Patrickios, C. S. Prog. Polym. Sci. 2011, 36, 1079-1097.

(51) Phillips, D. J.; Gibson, M. I. Biomacromolecules 2012, 13, 32003208.

(52) Nicolaÿ, R.; Marx, L.; Hémery, P.; Matyjaszewski, K. Macromolecules 2007, 40, 9217-9223.

(53) You, Y.-Z.; Manickam, D. S.; Zhou, Q.-H.; Oupický, D. J. Controlled Release 2007, 122, 217-225.

(54) Whittaker, M. R.; Goh, Y.-K.; Gemici, H.; Legge, T. M.; Perrier, S.; Monteiro, M. J. Macromolecules 2006, 39, 9028-9034.

(55) Gemici, H.; Legge, T. M.; Whittaker, M.; Monteiro, M. J.; Perrier, S. J. Polym. Sci., Part A: Polym. Chem. 2007, 45, 2334-2340.

(56) Frick, E. M.; Hillmyer, M. A. Macromol. Rapid Commun. 2000, 21, 1317-1322.

(57) Themistou, E.; Battaglia, G.; Armes, S. P. Polym. Chem. 2014, 5, 1405-1417.

(58) You, Y.; Hong, C.; Wang, W.; Lu, W.; Pan, C. Macromolecules 2004, 37, 9761-9767.

(59) Pratt, R. C.; Lohmeijer, B. G. G.; Long, D. A.; Lundberg, P. N. P.; Dove, A. P.; Li, H.; Wade, C. G.; Waymouth, R. M.; Hedrick, J. L. Macromolecules 2006, 39, 7863-7871.

(60) Bernaerts, K. V.; Du Prez, F. E. Prog. Polym. Sci. 2006, 31, 671722.

(61) Mecerreyes, D.; Humes, J.; Miller, R. D.; Hedrick, J. L.; Detrembleur, C.; Lecomte, P.; Jérôme, R.; San Roman, J. Macromol. Rapid Commun. 2000, 21, 779-784.

(62) Li, Y.; Armes, S. P. Macromolecules 2005, 38, 8155-8162.

(63) Wang, L.; Li, C.; Ryan, A. J.; Armes, S. P. Adv. Mater. 2006, 18, $1566-1570$.

(64) Sanda, F.; Endo, T. J. Polym. Sci., Part A: Polym. Chem. 2001, 39, $265-276$.

(65) Bailey, W. J.; Ni, Z.; Wu, S. R. Macromolecules 1982, 15, 711714.

(66) Schulze, T.; Klemm, E. Polym. Bull. 1993, 31, 409-414.

(67) Jin, S.; Gonsalves, K. E. Macromolecules 1997, 30, 3104-3106.

(68) d'Ayala, G. G.; Malinconico, M.; Laurienzo, P.; Tardy, A.; Guillaneuf, Y.; Lansalot, M.; D’Agosto, F.; Charleux, B. J. Polym. Sci., Part A: Polym. Chem. 2014, 52, 104-111.

(69) Evans, R. A.; Moad, G.; Rizzardo, E.; Thang, S. H. Macromolecules 1994, 27, 7935-7937.

(70) Evans, R. A.; Rizzardo, E. Macromolecules 1996, 29, 6983-6989.

(71) Phelan, M.; Aldabbagh, F.; Zetterlund, P. B.; Yamada, B. Polymer 2005, 46, 12046-12056.

(72) Agarwal, S. Polym. Chem. 2010, 1, 953-964.

(73) Chaumont, P.; Asgarzadeh, F.; Colombani, D.; Arotcarena, M.; Baudouin, A. Macromol. Chem. Phys. 1998, 199, 2577-2582.

(74) He, T.; Zou, Y.-F.; Pan, C.-Y. Polym. J. 2002, 34, 138-143.

(75) Hedir, G. G.; Bell, C. A.; Ieong, N. S.; Chapman, E.; Collins, I. R.; O'Reilly, R. K.; Dove, A. P. Macromolecules 2014, 47, 2847-2852.

(76) Delplace, V.; Tardy, A.; Harrisson, S.; Mura, S.; Gigmes, D.; Guillaneuf, Y.; Nicolas, J. Biomacromolecules 2013, 14, 3769-3779.

(77) Delplace, V.; Guegain, E.; Harrisson, S.; Gigmes, D.; Guillaneuf, Y.; Nicolas, J. Chem. Commun. 2015, 51, 12847-12850.

(78) Lutz, J.-F.; Andrieu, J.; Üzgün, S.; Rudolph, C.; Agarwal, S. Macromolecules 2007, 40, 8540-8543.

(79) Huang, J.; Gil, R.; Matyjaszewski, K. Polymer 2005, 46, 1169811706.

(80) Paulusse, J. M. J.; Amir, R. J.; Evans, R. A.; Hawker, C. J. J. Am. Chem. Soc. 2009, 131, 9805-9812.
(81) Warren, N. J.; Rosselgong, J.; Madsen, J.; Armes, S. P. Biomacromolecules 2015, 16, 2514-2521.

(82) Cunningham, V. J.; Ratcliffe, L. P. D.; Blanazs, A.; Warren, N. J.; Smith, A. J.; Mykhaylyk, O. O.; Armes, S. P. Polym. Chem. 2014, 5, 6307-6317.

(83) Blanazs, A.; Madsen, J.; Battaglia, G.; Ryan, A. J.; Armes, S. P. J. Am. Chem. Soc. 2011, 133, 16581-16587.

(84) Blanazs, A.; Armes, S. P.; Ryan, A. J. Macromol. Rapid Commun. 2009, 30, 267-277. 